\title{
Usage of Social Stories in Encouraging Social Interaction of Children with Autism Spectrum Disorder
}

\author{
Sunitha Balakrishnana ${ }^{\mathrm{a}}$, Aliza Alias ${ }^{\mathrm{b}}$ \\ ${ }^{a}$ Nexus International School Malaysia, Presint 15, 62050 Putrajaya, Malaysia. \\ bNational University of Malaysia, 43600 Bangi, Selangor, Malaysia. \\ E-mail: balakrishnan.s@nexus.edu.my
}

\begin{abstract}
Social story is a very popular intervention and used widely as a social learning tool for children with autism spectrum disorder (ASD). The purpose of this research was to investigate the usage of social stories in encouraging social interaction of children with ASD. The subjects for this study were 4 learners with ASD between the ages of 5 to 8 who were attending school in an inclusive setting. A single case experiment with A-B-A-B design was used for all 4 subjects. Three of the subjects showed great improvement in their ability to make friends. Improvement was also seen in their communication based on visual obeservation to the targeted behavior chart whereas 1 subject only showed very little improvement. The findings of this study suggest that the usage of social stories in improving the social interaction of children with ASD has a positive impact.
\end{abstract}

Keywords: Social story, autism spectrum disorder (ASD), social interaction, building friendship, inclusive setting.

Autism Spectrum Disorder (ASD) is a range of conditions that involves neurological developments, which mostly affects social interaction, communication and emotional development of a child. ASD includes Autistic Disorder, Asperger Syndrome and Pervasive Development Disorder. Most children with ASD often display repetitive behaviours or interests and some are also found to have a very good memory. Children with ASD will often have unusual responces to sensory experiences. In most circumstances, ASD can be noticed from the age of three. According to the "Autisme Society of America" (2000), about 2 to 6 children out of 1000 are normally diagnosed with ASD and ASD is more in boys as compared to girls.

Eugen Blueler was the first man who used the term 'autism' in 1910. He mentioned that the word 'autism' refers to the lack of interaction between people and the surrounding (Cook \& Willmerdinger, 2015). Autism now is more of a "developmental disorder". ASD can be treated but it can never be cured. Early diagnosis and intervention is very crucial in ensuring that a child with ASD progresses to his/her best ability.

Children with ASD have problem interacting with others especially children who are the same age with them. They find it difficult to build friendship and when they are approached to socialise, they are often seen displaying weird behaviours (Hall, 2009; KurcaaliIftar, 2007; Thompson, 2007). The main problem faced by children with ASD is social ability especially in making friends, responding approapriately to social conversations, changes in daily routines, understanding feelings of others and reacting appropriately in a social situation (Chamberlain, Kasari, \& Rotheram-Fuller, 2007; Cotugno, 2009; Reichow \& Volkmar, 2010; Thiemann \& Goldstein, 2010). The social interaction problems faced by children with ASD often prevent them from going through their day-to-day life. This problem will become more obvious when they start their schooling life and eventually face adulthood. Hence, social interaction intervention is one of the most critical interventions in the lives of children with ASD (Heward, 2013; Weiss \& Harris, 2001).

Autistic Society, UK (2000), relates ASD as the triad of impairments, which are social interaction (difficulties in having a social relationship, aloofness) social communication (difficulties in verbal and non-verbal communication, not able to understand facial ques, expressions and tone of voice) and social imagination (difficulties to engage in imaginative play). Although these impairments create social problems among children with ASD, it does not mean that they will never be able to learn these skills. They will still be able to learn these skills by watching their peers, copying or by using any other learning techniques.

The usage of social story has been seen as a very useful tool in assisting children with ASD in modification of behaviour and social interaction (Nurfarhana \& Normaliza, 2015). Social Stories was first introduced by Carol Gray in 1991. Gray was a consultant from Michigan who worked actively with 
ASD children. Social Stories are short descriptions of a particular situation, event or activity, which include specific information about what to expect in that situation and why. It normally comes in a storybook format, which makes it very suitable for children with ASD. It can be done with simple words or with illustrations.

According to Reynhout \& Carter (2006) there are three types of sentences in a Social Story. These sentences include "descriptive", "directive" dan "perspective" sentences. "Descriptive" sentences explain the social situation and gives trutful information about the issue. "Directive" sentences describe the desired responses to a social situation and "perspective" sentences describe the person's internal state, their feeling and thoughts in the said situation (Gray, 2000).

According to Ventimiglia (2007), although the researches done on the effects of social stories on behaviour modification was not very detailed, it was obvious that social stories was a useful tool in modification of difficult behaviour in children. The usage of interesting pictures and appropriate words made it even more successful. The effectiveness of social stories on children with special needs is evident through the many researches that have been done before (Sansosoti, Powell- Smith, \& Kinkaid, 2004). Nevertheless, it is not certain whether social stories are successful on its own or only successful when it is used together with other intervention.

More often than not, children with ASD are faced with three main problems, which are social issues, communication difficulties and behavioural concerns (White et al., 2012). However not all of them are faced with all these problems. Some only have one of the problems stated and some have more. Early intervention is the best way to help children with ASD face these problems (Lynch \& Simpson, 2010).

A range of techniques are used by teachers and professionals to assist children with autism to overcome the difficulties faced by them. These interventions are important to help children with ASD to access learning. The usage of the right technique is essential, as it would help the learning to be more efficient and systematic.

The purpose of this research was to investigate the usage of social stories to encourage social interaction of children with ASD (Schultz 2005), with the focus on building friendship and communication with other learners in the classroom.

Social story intervention is a new intervention that is used for children with ASD to improve their social interaction. It is a very unique intervention as it it personalised for each child and targets a particular behaviour that needs improvement at a particular time.

It is becoming a very popular intervention and is used to overcome behavioural issues faced by children with ASD, who very often need structured and clear rules in their daily life. It is eminent that social stories are beneficial in the lives of children with ASD in dealing with rutines and rules successfully (Crozier \& Tincani, 2007; Ventimiglia, 2007; Wright \& McCathren, 2012; Tanriady, Hartanti \& Aniva, 2013; Sani Bozkurt \& Varun, 2014).

\section{METHOD}

A single-case research design was used in this research. This design is commonly used in research of human behaviour to monitor changes that occur after an intervention. In this design, the subject serves as his/ her own control, rather than using another individual/ group.

An A-B-A-B design was used, whereby A represented the Baseline and $B$ represented the Intervention (Kratochwill, Hitchcock, Horner, Levin, Odom, Rindskopf, \& Shadish, 2010). During the baseline period, the subject was observed and data was recorded in the observation form. In the intervention period, the individualized social story was read to the subject and data was also recorded in the observation form.

During the first baseline, the subject was observed and data was recorded. This is called Baseline 1. In the first intervention stage, which is called Intervention 1 , the social story was introduced and the subject was monitored and data recorded accordingly. In the second baseline, which is called Baseline 2, the intervention was stopped and the subject was monitored again. Data obtained from this observation was recorded. The second intervention stage, which is Intervention 2 , the social story was read again and the subject was monitored once again. Once the intervention finished, the subject was monitored again to get a final outcome.

The sample for this research was selected from an international school with an inclusive setting where learners with special needs were included in the mainstream classroom. Subjects were selected for this research based on recommendation by the Inclusion Teachers.

A total of 4 learners, aged between 5 to 8 years old with ASD were selected after discussion with teachers and Personal Learning Assistants (PLAs). Three of the subjects were boys and one was a girl. All four subjects had target behavior of positive peer interaction and response to peer initiation.

Observations were mostly done in the Early Years, Year 1 and Year 2 classrooms over the period of 5 weeks. Some observations were also done during play time in the field and play area. Most observations were done by the Inclusion Teacher and the subject's Personal Learning Assistants (PLA), who are teachers 
Table 1. Subject's characteristics

\begin{tabular}{lll}
\hline Age / Gender & Diagnosis & Problem Behaviour \\
\hline Subject $1: 5$ years old / boy & Autism Spectrum Disorder with delay in speech & $\frac{\text { Limited positive peer }}{\text { interaction and response to }}$ \\
\hline Subject $2: 7$ year old / boy & Autism Spectrum Disorder with features of ADHD & $\frac{\text { peer initiation }}{\text { Limited positive peer }}$ \\
\hline Subject $3: 7$ year old / girl & Social (Pragmatic) Communication Disorder & peer initiation \\
\hline Subject $4: 8$ year old / boy & Autism Spectrum Disorder with learning difficulties & Limited positive peer \\
\cline { 2 - 3 } & & interaction and response to \\
\hline
\end{tabular}

That are employed by parents to assist their child with his/her learning in the school on a more personalised manner. Teacher Assistants were also used to record some of the observations during the research.

Social stories for each subject were individually created and personalised to suit each of his/her need. Seven teachers, six teaching assistants and 3 PLAs were involved in the observation. They were briefed about the entire process and they were trained on how the observation sheets need to be recorded. A shared google document was created and all observations were filled in this document on a daily basis.

\section{FINDING AND DISCUSSION}

\section{Findings}

Observation form, for this research was done in collaboration with the teachers and the specialists working with the subjects.

Overall there was an increase in positive response of all four subjects. All four of them started to show positive peer interaction and response to peer initiation. Subjects 2, 3 and 4 showed better response compared to subject 1. Subject 2 displayed the most positive peer interaction followed by subject 3, 4 and 1 . Throughout the 5 weeks, subject 2 managed to participate and ask peers to play in a positive way for 20 times, subject 3 achieved it for 18 times, subject 4 did it 13 times and subject 1 managed to do it 8 times.

\section{Subject 1}

Subject 1 is a 5-year-old boy with ASD and speech delay. The social story that was used for this subject was initiating conversations with peers and responding to peers' conversation in the right manner. Before the intervention, he was not able to have a conversation with any of his peers. He was always found playing alongside his peers but never together with them. During the intervention, he managed to start initiating conversations especially when he wanted to join in to play with his friends. Although the frequency of this positive interaction was not very high, he nevertheless showed some improvement and managed to start having positive interactions with his peers.

From Figure 1, we are able to see that there is some improvement in social interaction for subject 1. During baseline 1, he did not show any positive interactions with his peers at all. After the first intervention, he managed to initiate conversations with peers and respond to peers conversation in the right manner for 2 times in the week. This is a great achievement for this subject as prior to this, he would just play on his own and not interact at all. During Baseline 2, where the social story was not read to the subject, his positive interaction reduced to only 1 time in the week. However, since this was without any prompt, it was considered as successful as well. During intervention 2 , he showed more improvement and was seen displaying positive peer interaction for a total of 3 times in the week. During the last week, which was the maintenance period, the frequency of his positive peer interaction reduced but however, with his background and ability, it was considered a huge success. 
Figure 1. Frequency of Positive Peer Intervention

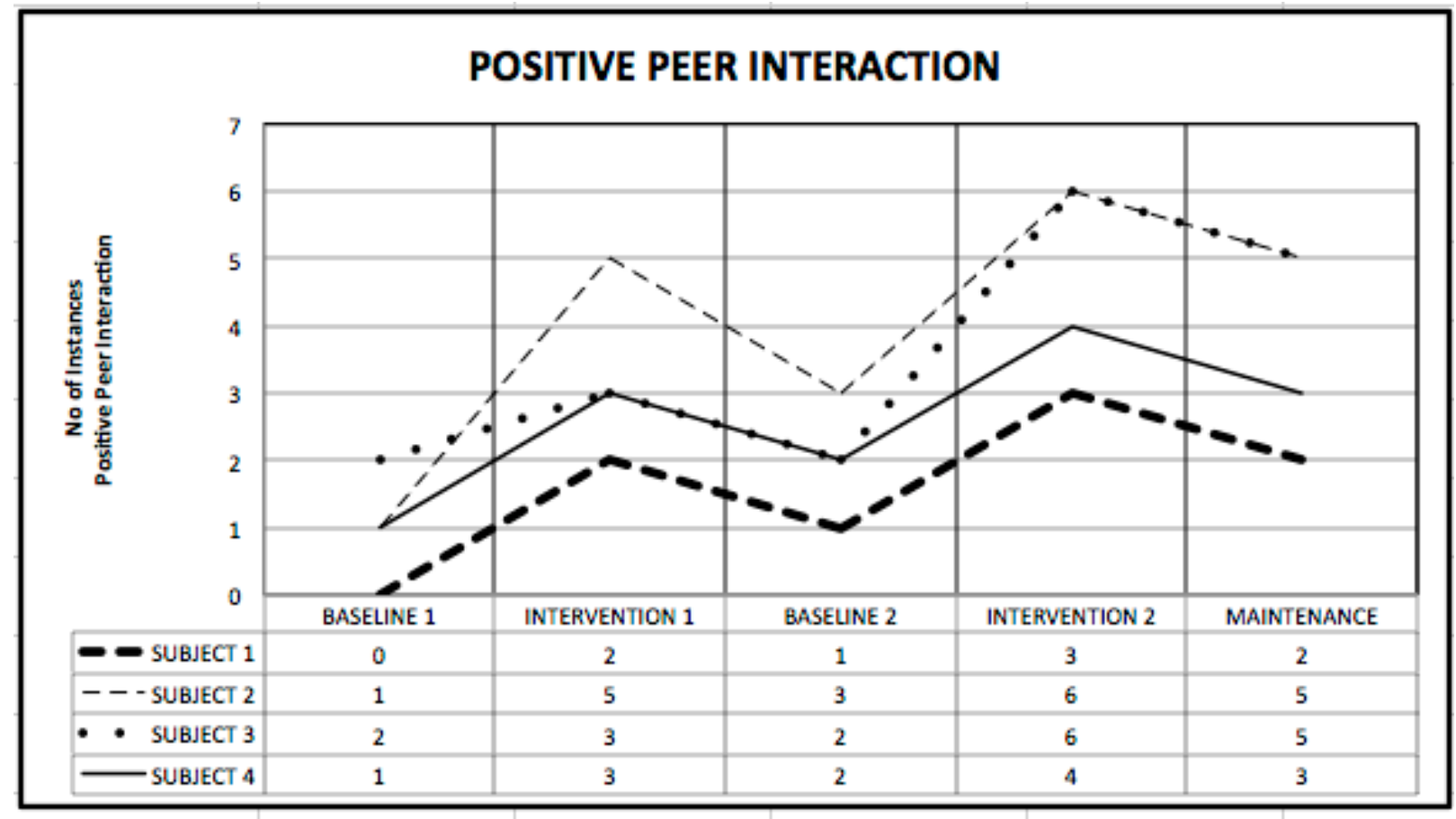

\section{Subject 2}

Subject 2 is a 7-year-old boy with ASD and features of ADHD. He is a very articulate boy and is always able to express his needs approapriately. However, he struggles to have conversations with his friends and finds it really hard to play together with his peers. The social story that was used for him is on building friendship and maintaining appropriate conversations with his peers. Subject 2 responded very well to the social story intervention and was able to show positive peer interactions frequently.

This subject showed the most improvement out of all the other subjects. During baseline 1, he was only seen displaying positive peer interaction in building friendship and maintaining appropriate conversations with his peers once. However, in the intervention 1 period, the frequency of his positive peer interaction increased to 5 times in the week. During baseline 2, eventhough the social story was not read to him, he still managed to keep up his positive peer interaction whereby the frequency was 3 times in the week. Intervention 2 period was the most successful as he managed to maintain his positive peer interaction and displayed it 6 times in the week. This was the most successful week for him. He also managed to maintain his success during the maintenance week whereby he was seen displaying the targeted behaviour 5 times in the week.

\section{Subject 3}

Subject 3 is a 7-year-old girl with Social (Pragmatic) Communication Disorder. She also shows traits of autism but never had an official diagnosis of ASD. She is a very intelligent girl with learning ability above her age. She reads and writes very well but struggles socially. She is often found playing on her own as she was never able to join in with her peers. The targeted social story for her was joining in her friend to play and using appropriate words when she is talking to her friends. This subject also responded very well to the social story intervention and was able to display positive improvement over the 5 weeks of intervention.

Before intervention had started, this subject managed to join in her friends to play and used appropriate words when she is talking to her friends at a very reduced rate. During intervention 1, she improved and was able to show positive peer interaction 3 times in the week. When the social story was not read during baseline 2, the frequency reduced by 1 , but she still managed to show some positive peer interaction. During intervention 2, her targeted behaviour improved tremendously, from 2 times to 6 times. This was a great improvement and she also managed to maintain her progress during the maintenance period where she displayed the positive peer interaction 5 times in that week. 


\section{Subject 4}

Subject 4 is an 8 -year-old boy with ASD. He struggles with learning in the classroom and has a very short attention span. He needs a lot of one to one support in the classroom and also struggles with interacting with his peers. He often tries to join in his peers in a group but usually does not know or is unaware of the right words that he needs to use during a conversation with his peers. This often leads to his peers not wanting him in their group and eventually he would be seen doing things on his own. The social story used for him was on communication with friends and ways to join in a playgroup. Subject 4 responded well to the social story intervention. He was able to use better words when he was with his peers and also join in a group for a longer period of time.

This subject only showed positive peer interaction once during baseline 1 but showed huge improvement during intervention 1 where he displayed his targeted behaviour of communicating with friends and joining in a playgroup 3 times in the week. During baseline 2 , although the social story was not read to him, he managed to maintain this positive peer interaction and was observed showing this 2 times in the week. During intervention 2, where the social story was read to him again, he displayed positive peer interaction 4 times and also maintained this during the maintenance period.

\section{Discussion}

The findings of this study shows that the usage of social story does help improve the social interaction of children with ASD. The benefits of social stories have been researched widely and have in most cases shown positive improvement or success (Sansosoti, PowellSmith, \& Kinkaid, 2004).

This is also seen in this research whereby 3 out of 4 participants showed huge success in improving the targeted behaviour. However, it is unclear whether the success is solely because of the social story intervention or was it a combination of several other interventions as well.

For subject 1 , the success was very minimal compared to the other 3 subjects. If the social story was accompanied by prompt, it would have been more successful for him. According to the research done by (Crozier \& Tincani, 2007), when verbal prompts were added in the intervention, the subject demonstrated higher levels of the target behavior compared to baseline and the Social Story alone condition. Social story that are used together with other interventions have proven to be more efeective (More, 2010; Hutchins \& Prelock , 2013; Tanriady, 2013).

The usage of social story should be very consistent. The story should be read to the subject daily in order to get the most successful outcome. Even after the study has ended, the social story should be re-visited from time to time to ensure that the target is consistently achieved. In the event where a reversal of behaviour is noticed, the social story should be read again to serve as a reminder to the subject.

Gray \& Garand (1993) suggested that the length of time a child needs for a Social Story to be successful may vary from one child to another. To date there has not been any evaluation on the optimal length of intervention or the relevant characteristics of participants that could determine an appropriate duration of use (Crozier \& Tincani, 2007).

The study was restricted to only 4 participants, which may not be a very good indication of the success of social story intervention. It would have been better if more participants with a wider background were recruited. This would have shown a better indication of the success of the usage of social stories.

Besides that, we only used physical social stories that were created for the subjects. Consideration should have been given to use a wider variety of social stories, which include "comic strips", "video self modelled" (VSM), usage of other story apps on i-pad such a Book Creator, Voki, Tellagami and others. This may have been more suitable especially for subject 1 , who was the youngest among all the subjects and was less verbal compared to the rest.

\section{CONCLUSION AND SUGGESTION}

The findings of this study support the usage of social stories in encouraging social interaction of children with ASD. Social stories were effective as it helped the subjects to improve their social interaction skills especially in their ability to make friends and improve communication. Social stories should be used as part of the education system to help with behaviour modification especially for children with needs. In particular, teachers, parents, and other care givers can use this intervention to improve the social skills of children with ASD. Social story intervention should be a collaborative effort whereby all teachers who work with the child and their parents should play a part in ensuring that the intervention is carried out efficiently. This will ensure consistency and with consistency, the outcome will be more successful.

For future research, this study could also be extended and used for children with other needs such as children with Attention-Deficit Hyperactivity Disorder (Novita \& Siswatithe, 2010) or other intellectual and developmental disabilities (Eckelberry, 2007). Consideration should also be given to the usage of social story together with prompts which would serve as a reminder to the child when the child is not displaying the targeted behaviour. 


\section{REFERENCES}

Chamberlain, B., Kasari, C., \& Rotheram-Fuller, E. (2007). Involvement or isolation? The social networks of children with autism in regular classrooms. Journal of Autism and Developmental Disorders, 37(2), 230-242.

Cook, K. A., \& Willmerdinger, A. N., (2015). "The History of Autism". Narrative Documents. Book 1. Retrieved from http://scholarexchange.furman. edu/schopler-about/1

Cotugno, A. J. (2009). Social competence and social skills training and intervention for children with autism spectrum disorders. Journal of autism and developmental disorders, 39(9), 1268-1277.

Crozier, S., \& Tincani, M. (2007). Effects of social stories on prosocial behavior of preschool children with autism spectrum disorders. Journal of autism and developmental disorders, 37(9), 1803-1814.

Eckelberry, E. (2007). Using social stories with children with autism, learning disabilities and $A D H D$. Retrieved from http://www.coe.ohiou. edu/resources /documents/Eckelberry-F07.pdf.

Gray, C. A., \& Garand, J. D. (1993). Social stories: Improving responses of students with autism with accurate social information. Focus on Autistic Behavior, 8(1), 1-10.

Gray, W. D. (2000), The Nature and Processing of Errors in Interactive Behaviour. Cognitive Science, 24(2): 205-248.

Hall, L. J. (2009). Autism spectrum disorders: From theory to practice. Upper Saddle River, NJ: Pearson Merrill Prentice Hall.

Heward, W. L. (2013). Exceptional children: An introduction to special education (10th ed.). New York: Pearson.

Hutchins, T. L., \& Prelock, P. A. (2013). The social validity of Social Stories ${ }^{\mathrm{TM}}$ for supporting the behavioural and communicative functioning of children with autism spectrum disorder. International journal of speech-language pathology, 15(4), 383-395.

Kırcaali-Iftar, G. (2007). Otizm spektrum bozukluğu. Istanbul: Daktylos.

Kratochwill, T. R., Hitchcock, J., Horner, R. H., Levin, J. R., Odom, S. L., Rindskopf, D. M., \& Shadish, W. R. (2010). Single-case designs technical documentation. Retrieved from http://ies.ed.gov/ ncee/wwc/pdf/wwc_scd.pdf.

Lynch, S. A. \& Simpson, C. G. (2010). Social skills: laying the foundation for success. Dimensions of Early Childhood, 38(2), 3-12.
More, C. M. (2010). Effects of social story interventions on preschool age children with and without disabilities, University of Nevada Las Vegas.

Novita, N., \& Siswati, S. (2010). Pengaruh social stories terhadap keterampilan sosial anak dengan attention-deficit hyperactivity disorder (adhd) studi eksperimental desain kasus tunggal di sekolah alam ar-ridho semarang. Jurnal Psikologi Undip, 8(2), 102-116.

Nurfarhana, S. R,. \& Normaliza, A. R. (2015). Penerapan elemen penceritaan dalam teknik pembelajaran kanak-kanak sindrom asperger, Jabatan Bahasa Melayu, Fakulti Bahasa Moden Dan Komunikasi, Universiti Putra Malaysia, 43400 Serdang, Selangor.

Reichow, B., \& Volkmar, F. R. (2010). Social skills interventions for individuals with autism: evaluation for evidence-based practices within a best evidence synthesis framework. Journal of Autism and Developmental Disorders, 40(2), 149-166.

Reynhout, G., \& Carter, M. (2006). Social Stories for children with disabilities. Journal of Autism and Development Disorder, 36(4), 445-469.

Sani Bozkurt, S., \& Vuran, S. (2014). An analysis of the use of social stories in teaching social skills to children with autism spectrum disorders. Educational sciences: Theory and Practice, 14(5), 1875-1892.

Sansosti, F. J., Powell-Smith, K. A., \& Kincaid, D. (2004). A research synthesis of social story interventions for children with autism spectrum disorders. Focus on Autism and Other Developmental Disabilities, 19(4), 194-204.

Schultz, R. T. (2005). Developmental deficits in social perception in autism: the role of the amygdala and fusiform face area. International Journal of Developmental Neuroscience, 23(2), 125-141.

Tanriady, S., Hartanti, \& Aniva (2013). Pengaruh Social Stories Terhadap Keterampilan Komunikasi Pragmatis Anak dengan Gangguan Asperger (Doctoral dissertation, Fakultas Psikologi UBAYA).

Thiemann, K. S., \& Goldstein, H. (2010). Social stories, written text cues, and video feedback: Effects on social communication of children with autism. Journal of applied behavior analysis, 34(4), 425446.

Thompson, T. (2007). Making sense of autism. Baltimore: Paul H. Brookes Publishing Co.

Ventimiglia, A. (2007). The Effects of Social Stories on the Social Interaction and Behavior of Students with Autism Spectrum Disorders. St. John Fisher College. 
Weiss, M. J., \& Harris, S. L. (2001). Teaching social skills to people with autism. Behavior Modification, 25(5), 785-802.

White, M. L., Smith, J. D., Smith, T. E. C., \& Stodden, R. (2012). Autism spectrum disorders: Historical, legislative, and current perspectives. Educating students with autism spectrum disorders, 3-12.

Wright, L. A., \& McCathren, R. B. (2012). Utilizing social stories to increase prosocial behavior and reduce problem behavior in young children with autism. Child Development Research, 2012. 